\title{
Identification of chosen apoptotic (TIAR and TIA-1) markers expression in thyroid tissues from adolescents with immune and non-immune thyroid diseases
}

\author{
A. Bossowski ${ }^{1}$, B. Czarnocka ${ }^{2}$, K. Bardadin ${ }^{3}$, A. Moniuszko ${ }^{4}$, A. Lyczkowska ${ }^{2}$, \\ J. Czerwinska ${ }^{3}$, J Dadan 5 , A. Bossowska ${ }^{6}$
}

${ }^{1}$ Department of Paediatrics, Endocrinology, Diabetology with Cardiology Division, ${ }^{5}{ }^{\text {st }}$ Department of General Surgery, Medical University in Bialystok, Poland

${ }^{2}$ Department of Biochemistry and Molecular Biology, ${ }^{3}$ Department of Patomorphology, Medical Center of Postgraduate Education, Warsaw, Poland

${ }^{4}$ Department of Infectious Diseases and Neuroinfections, Medical University in Bialystok, Poland

${ }^{6}$ Division of Cardiology, Internal Affairs and Administration Ministry Hospital in Białystok, Poland

\begin{abstract}
The aim of this study was to estimate sodium iodide symporter (NIS) and thyroid peroxidase (TPO) expression in thyrocytes from patients with GD and no-toxic multinodular goitre (NTMG) in relationship with apoptotic (TIAR and TIA-1) markers. The investigation was performed on thyroid cells isolated from postoperation thyroid tissues from 15 patients aged 12-21 years old with GD and 15 cases aged 13-21 years old with NTMG. Detection of NIS and TPO was performed by immunohistochemistry. Analysis of apoptotic markers in thyroid tissues was performed using antibodies to TIAR and TIA-1 by Western Blot and immunohistochemistry. Identification of proapoptotic TIAR and TIA-1 molecules in the thyroid tissues revealed a higher expression of both proteins in patients with Graves' disease $(+++;+$, respectively) in comparison to patients with NTNG (+; 0). In addition, TIAR expression was detected in three bands [p50, p42, p38 (kDa)] and TIA-1 in two bands [p22, p17 (kDa)]. using Western Blot test in patients with thyroid autoimmune diseases. In patients with NTNG expression of both apoptotic proteins was lower and identified in single bands: $42(\mathrm{kDa})$ for TIAR and 17 (kDa) for TIA-1. The analysis of expression of NIS and TPO in thyroid follicular cells was higher in patients with Graves' disease in compared to their detection in patients with NTMG. In addition, degree of thyroid antigen expression positive correlated with amount of proapoptotic markers (TIAR, $\mathrm{p}<0.001$; TIA-1, $\mathrm{p}<0.025$ for NIS; TIAR, $\mathrm{p}<0.012$ for TPO). We conclude that elevated expression of NIS and TPO in Graves' disease is associated with higher stimulation and activation of apoptosis in thyroid follicular cells during autoimmune process.
\end{abstract}

Key words: thyrocytes, apoptosis, Graves' disease, TIAR

\section{Introduction}

The course of Graves' disease (GD) is associated with the inflow of lymphocytes to the thyroid gland and dysregulation of the immune system characterized by reaction to thyroid antigens (peroxidase, thyroglobulin, TSH receptors and Na+/I- symporter). After activation they shift to the inflamed thyroid gland, thus

Correspondence: A. Bossowski, Dept. of Paediatrics, Endocrinology, Diabetology with Cardiology Division, Medical University of Białystok, Poland, Waszyngtona Str. 17, 15-274 Białystok, Poland; tel.: (+4885) 7450730,

fax.: (+4885) 7450730, e-mail: abossowski@hotmail.com leading to the production of cytokines which can stimulate activity of thyrocytes and increase expression on intracellular proapoptotic markers such as TIAR and TIA-1.

T-cell intracellular antigen 1 (TIA-1) and TIA-1related protein (TIAR) are the RNA-binding proteins. They consist of three RNA recognition motifs (RRMs) and a glutamine-rich carboxyl-terminal domain [1].

Both proteins play role in nuclear and cytoplasmic RNA metabolism, in pre-mRNA splicing and mRNA translation. TIA-1 has been identified as an important splicing regulator in mammals. It was proven that TIA-1 regulates the alternative pre-mRNA splicing of various human and Drosophila genes (FGFR-2, msl-2, 
TIAR, cystic fibrosis transmembrane conductance regulator and Fas) through binding to U-rich stretches, facilitating atypical 5 -splice site recognition by U1 small nuclear ribonucleoprotein $[2,3]$.

TIA-1 has also been well characterized as a translational regulator. TIA-1 and TIAR are both able to bind to the 3-untranslated regions of the translational regulatory AU-rich elements of tumor necrosis factor, human matrix metalloproteinases-13, cyclooxygenase2,2-adrenergic receptor, mitochondrial cytochrome c, GADD45 and -F1-ATPase mRNAs [4-10].

These both protein may also promote cellular and virus-induced apoptosis, to be implicated in viral replication and to be required for DT40 cell viability. TIA1 plays also important functions in apoptotic cell death and in adapting the cellular response to metabolic stress and inflammation. TIAR is translocated from the nucleus to the cytoplasm during Fas- mediated apoptosis. TIA-1 is a specific substrate for the Fas- activated protein serine/ threonine kinase [10].

The isoforms of both mTIA-1 and mTIAR are predominantly expressed in brain, spleen and testis and mTIAR is also expressed in liver and lung. mTIA-1 and mTIAR are not expressed or only very weakly, in the other tissues tested such as heart, skeletal muscle and kidney [11].

The aim of this study was to estimate sodium iodide symporter (NIS) and thyroid peroxidase (TPO) expression in thyrocytes from patients with GD and no-toxic multinodular goiter (NTMG) in relation to the apoptotic markers.

\section{Material and methods}

Patients and study material. The study was performed in a group of 30 adolescent patients ( 8 boys and 22 girls) aged 8-21 years with GD ( $\mathrm{n}=15$, mean age $13.9 \pm 3.5$ years) and nontoxic nodular goiter (NTNG; $\mathrm{n}=20$, mean age $15.8 \pm 2.2$ years) hospitalized in the Department of Pediatrics, Endocrinology, Diabetology with Cardiology Division, Medical University of Białystok and in the Department of Pediatric Endocrinology and Diabetology, Poznań University of Medical Sciences. The patients underwent total or subtotal thyroidectomy in the $1^{\text {st }}$ Department of General Surgery, Medical University of Białystok or in the Department of Pediatric Surgery, Poznań University of Medical Sciences.

The diagnosis was established based on clinical examinations confirmed by laboratory, ultrasonographic and scintigraphic investigations with the use of $\mathrm{I}^{131}$ (in case of nodular goiter with symptoms of hyperthyroidism). Additionally, fine-needle aspiration biopsies of nodular goiter were performed in the Department of Pathological Anatomy, Medical University of Białystok. The qualifying criteria for patients with GD were as follows: large goiter, presence of ophthalmopathy, antibodies against receptor for thyroid stimulating hormone (TRAb) $>5$, positive titers of antithyroid peroxidase (anti-TPO) and anti-thyroglobulin (anti-TG) antibodies persisting over 2-3 months since the diagnosis of thyroid-stimulating hormone $(\mathrm{TSH})<0.45$.

Methimazole therapy, at the initial dose of $0.5-1.0 \mathrm{mg} / \mathrm{kg} / \mathrm{day}$, was used in combination with propranolol $0.5-1.0 \mathrm{mg} / \mathrm{kg} /$ day to treat hyperthyroidism in the course of GD and toxic nodular goiter. A further reduction in methimazole dose and obtaining euthyrosis prior to surgery depended on clinical-biochemical parameters. Average daily doses of this antithyroid drug were $10-15 \mathrm{mg}$. Some of the GD patients underwent combined treatment (antithyroiddrug with thyroxine at a dose of 50-100 $\mu \mathrm{g} /$ day).

The function of the thyroid gland in patients with GD (as well as in nodular goiter) was assessed at the time of diagnosis and prior to surgery. Thyroid function was evaluated based on thyroid hormones and TSH tests performed jointly with the measurement of titers of antithyroid antibodies (ATPO, ATG, TRAK). The expression of proapoptotic proteins was identified in tissue material obtained from patients with immune and nonimmune disorders.

Determination of the antithyroid antibody titers and thyroid hormone concentration. Blood for analysis was collected on empty stomach in the morning hours from the basilic vein and centrifuged for $10 \mathrm{~min}$ at 2,000 rotations $/ \mathrm{min}$. Sera were stored at $-20^{\circ} \mathrm{C}$ until the required number was collected. Immunodiagnostic test Varelisa (Variable Enzyme Linked Immno Sorbent Assay, Pharmacia Upjohn Diagnostics, GmbH \& Co.KG., Freiburg, Germany) was used to determine anti-peroxidase antibodies (antiTPO) and anti-TG antibodies in the sera, using human microsomal antigen and human thyroglobulin, respectively. The results were read on a photometer (STAT FAX 303 PLUS, ANALCOGBG), at $450 \mathrm{~nm}$ of light wavelength for which absorption values were proportional to the level of anti-TPO or anti-TG antibodies. The radioreceptor method (TRAK-human, Brahms Diagnostica, GmbH, Berlin, Germany) was employed to assess TRAb in blood serum. The TRAb level was negative at the values $<1 \mathrm{U} / 1$, doubtful between 1.0 and $1.5 \mathrm{U} / 1$ (grey zone) and positive above $1.5 \mathrm{U} / 1$.

Determination of serum thyrotropin hormone (TSH) was done using a mini-analyzer VIDAS (bioMérieux) and VIDAS TSH test, being a combination of the immunoenzymatic method and final fluorescence measurement (ELFA). In the permanent phase, antiTSH mouse monoclonal antibodies were used. Normal values for TSH ranged between 0.32 and $5.0 \mu \mathrm{IU} / \mathrm{ml}$. Serum levels of free thyroxine (fT4) and free triiodothyronine (fT3) were determined on a mini-analyzer VIDAS based on VIDAS fT4 and VIDAS fT3 tests that combine the immunoenzymatic method with the final measurement of fluorescence (ELFA).

Normal values ranged between 0.71 and $1.55 \mathrm{ng} / \mathrm{dl}$ for fT4 and between 2.6 and $5.4 \mathrm{ng} / \mathrm{dl}$ for fT3.

SDS-PAGE and Western Blotting. Tissue samples were homogenized in an ice-cold buffer $(250 \mathrm{mM}$ sucrose, $20 \mathrm{mM}$ Tris-HCl, pH 7.4, 1 mM EDTA) containing a cocktail of protease inhibitors (Roche Diagnostics, GmbH, Mannheim, Germany). Homogenates were centrifuged at $1,000 \mathrm{~g}$ for $15 \mathrm{~min}$ at $4^{\circ} \mathrm{C}$, then at $100,000 \mathrm{~g}$ for $60 \mathrm{~min}$ at $4^{\circ} \mathrm{C}$. The resulting pellets containing particulate fractions were recovered, resuspended in $20 \mathrm{mM}$ Tris$\mathrm{HCl}, \mathrm{pH} 7.4$ with $1 \mu \mathrm{g} / \mathrm{ml}$ phenyl-methylsulphonyl fluoride and kept at $-80^{\circ} \mathrm{C}$. The protein concentrations were evaluated by the bicinchronic acid protein assay reagent (Pierce Chemical, Co., Rockford, Ill., USA).

A total of $75 \mu \mathrm{g}$ of crude membrane proteins was mixed with a protein buffer $(0.25 \mathrm{mM}$ Tris- $\mathrm{HCl}, \mathrm{pH} 6.8,20 \%$ glycerol, $4 \%$ SDS, and $0.1 \%$ bromophenol blue) and incubated with $0.125 \mathrm{M}$ dithiothreitol for $30 \mathrm{~min}$ at $37^{\circ} \mathrm{C}$. Each sample was loaded into individual wells and electrophoresed on a $9 \%$ acrylamide, using the SDS-PAGE method. Proteins were electrotransferred to immunoblot PVDF membranes (Bio-Rad Laboratories, Hercules, Calif., USA), which were then saturated with $5 \%$ powdered milk in PBS-Tween. Western blotting experiments were subsequently carried out by incubating the blotted membranes with mouse monoclonal anti-human TIAR and TIA-1 antibodies (BD Biosciences Pharmingen) diluted according to the manufacturer's suggestion overnight at $4^{\circ} \mathrm{C}$. After three washings in PBSTween for $10 \mathrm{~min}$, 


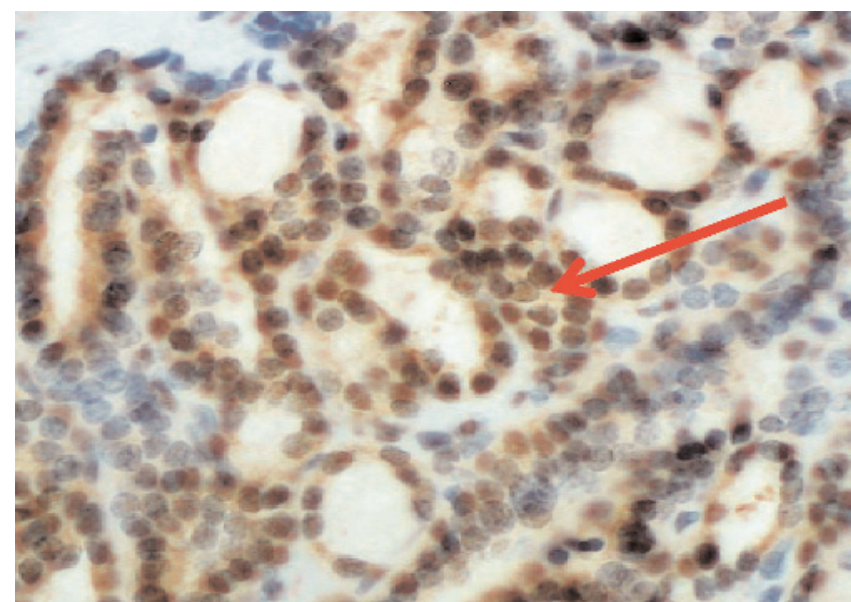

Fig. 1. Immunohistochemical identification of TIAR molecule in thyrocytes from a representative patients with GD. Expression of TIAR protein $(+++)$.

the membranes were incubated with affinity purified anti-mouse antibody labeled with horseradish peroxidase (Jackson ImmunoResearch Laboratories, West Grove, Pa.,USA) for $1 \mathrm{~h}$ at room temperature under shaking. After extensive washing, membranes were developed with a SuperSignal West Pico (Pierce). The visualization of proteins was performed by chemiluminescence detection procedure - exposure to BioMax Ms film (SigmaAldrich, Corp., St. Louis, Mo., USA). The secondary antibody controls were included in the series of Western blots. Immunoblots were reprobed with $\beta$-actin antibody 1:10,000 (mouse monoclonal antibody; Sigma) for normalization.

Immunohistochemistry. Tissue sections of $3 \mu \mathrm{m}$ were mounted on silane-coated glass slides, deparaffinized in xylene, and rehydrated via graded ethanols to water. Then the antigen was heat retrieved at $95-99^{\circ} \mathrm{C}$ for $20 \mathrm{~min}$ in TRS $\mathrm{pH} 6.0$ and after endogenous peroxidase block slides were incubated with anti-NIS, antiTPO\#47, anti-TIAR and anti-TIA-1 (at a concentration according to the manufacture formula) overnight at $4^{\circ} \mathrm{C}$; after washing sections were incubated with LSAB+ kit (DAKO).

All primary antibodies used were commercially available (BD Biosciences). The reaction was developed with DAB chromogene. The slides were counterstained with Mayer's hematoxylin. The specificity of the immunostaining was checked by omission of single steps in the protocol, replacement of the primary antibody with preimmune serum and peptide competition tests. Slides that showed no staining were considered negative, all other slides with staining were considered positive. Two pathologists independently evaluated reaction on randomly numbered slides. Expression index was created by classifying the samples into three categories based on the percentage of positive cells in the total number of cells counted per field. Grade I $(+)$ included samples with less than $10 \%$ positive cells, grade II $(++)$ samples had $10-50 \%$ positive cells, and grade III $(+++)$ samples showed more than $50 \%$ positive cells.

Ethical issues. Our study was approved by the Committee for Ethics and Supervision on Human and Animal Research of the Medical University of Białystok.

Statistical analysis. The results were analyzed using Statistica 8.0 software. The mean values of immune parameters between groups were evaluated using Student's t test, U Mann-Whitney's test or Fisher's exact probability test. Correlation was assessed by Spearman's signed ranks test. $\mathrm{P}<0.05$ was considered significant.

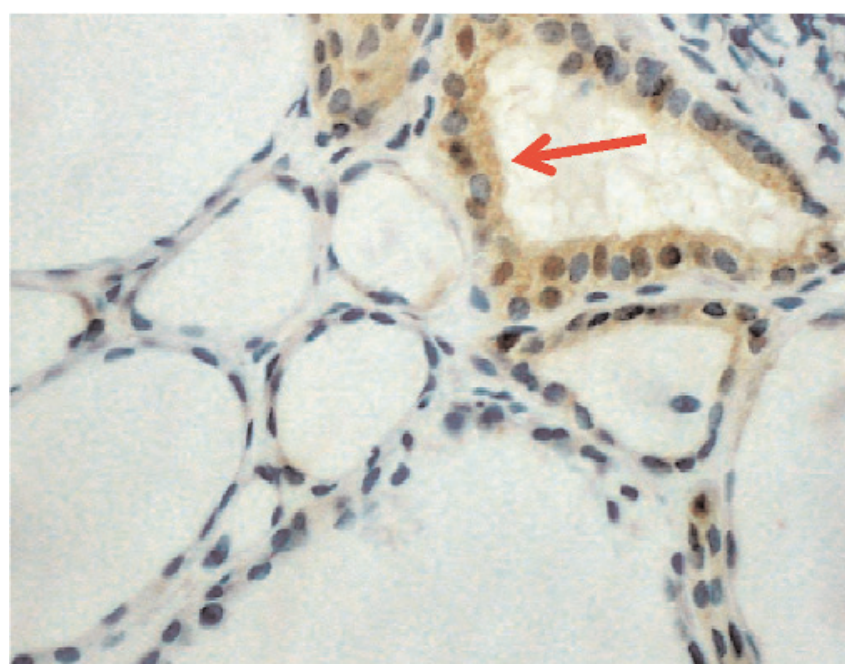

Fig. 2. Immunohistochemical identification of TIAR molecule in thyrocytes from a representative patients with NTMG. Expression of TIAR protein $(+)$.

\section{Results}

Table 1 presents the characteristics and laboratory findings of patients with GD (prior to methimazole therapy and during clinical-biochemical euthyreosis before surgery) or with NTMG (before surgery). Patients with nodular lesions above $1 \mathrm{~cm}$ in size seen on ultrasonography underwent fine-needle aspiration biopsy, which revealed benign changes in the form of 'colloid nodular goiter'. Scintigraphy additionally performed in 3 patients with nodular goiter and clinical symptoms of hyperthyroidism showed a selective increase in the accumulation of radioactive iodine within the area of single nodular lesions. Postoperative tissue material was used to identify proapoptotic regulatory proteins of the TIAR and TIA family by means of immunohistochemistry and Western blot analysis.

Identification of proapoptotic TIAR (TIA-1 related protein) molecule in the thyroid tissues revealed a higher expression of this protein in patients with Graves' disease (+++) in comparison to patients with NTNG (+) (Figs. 1 and 2). The elevated expression of TIAR in the thyroid tissue of patients with GD was observed mainly in hyperfunctional thyrocytes (with higher epithelium). The expression of TIA-1 molecule was detected only in patients with Graves' disease $(+)$ in lymph nodes with germinal centers.

The tissue material was additionally subjected to Western blot analysis, which in GD patients showed the presence of TIA- 1 in the band p22, p17 (kDa)] (Fig. 3a). In group of patient with NTMG presence of TIA-1 in the band $17(\mathrm{kDa})$ were observed (Fig. 3b). In GD patients, Western blot analysis showed TIAR expression in band p50, p42, p38 (kDa) (Fig. 4a). In patients with NTNG, the degree of expression of TIAR 


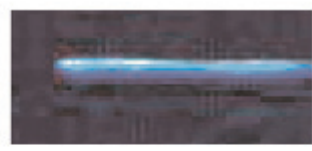

(kDa)

p22

p17

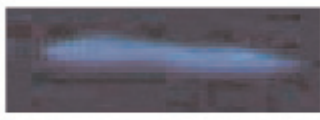

b

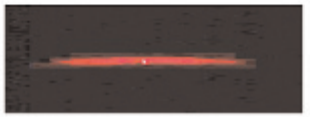

p17

Fig. 3. Identification of apoptotic TIA-1 protein by Western Blot method in a representative patients with Graves' disease (a) and non-toxic multinodular goiter (b).

a

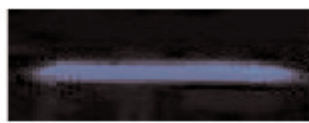

(kDa)

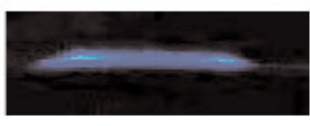

$\mathrm{p50}$

$\mathrm{p} 42$

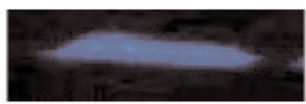

p38

b

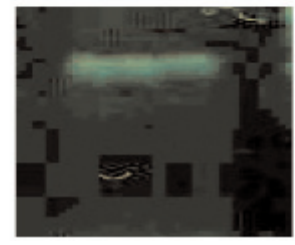

p42

Fig. 4. Identification of apoptotic TIAR protein by Western Blot method in a representative patients with Graves' disease (a) and non-toxic multinodular goiter (b).

proteins was lower and referred to band $42(\mathrm{kDa})$ (Fig. 4b). Each thyroid tissue sample obtained from our study patients underwent assessment for the presence of $\beta$-actin using the Western blot method, which confirmed that the tissues were not degraded and indicated high-quality analyses (Fig. 5). This study showed increased expression of proapoptotic markers in thyroid tissues from Graves' patients in comparison to patients with nontoxic nodular goiter.

The relationship between expression of NIS and TPO and the expression of apoptosis regulatory molecules of the TIA-1 family were taken into consideration. The expression of NIS and TPO in thyroid follicular cells was higher in patients with Graves' disease $(+++,+++$, respectively) in comparison with their detection in patients with NTMG $(+,+$, respectively)
Table 1. Clinical characteristics of the examined patients. GD Graves' disease NTMG - non-toxic mulitnodular goiter, ${ }^{*}$ - statistical significance between group with GD and group with NTMG.

\begin{tabular}{|c|c|c|c|}
\hline & $\begin{array}{l}\text { Group with } \\
\text { GD }\end{array}$ & $\begin{array}{c}\text { Group with } \\
\text { NTMG }\end{array}$ & $* \mathrm{p}$ \\
\hline Age (ycars) & $17.1 \pm 4.3$ & $16.0 \pm 5.2$ & NS \\
\hline $\mathrm{n}$ & 15 & 15 & \\
\hline Weight (kg) & $59 \pm 7$ & $63 \pm 8$ & NS \\
\hline Height (cm) & 1.75 & 1.76 & NS \\
\hline $\mathrm{BS} \wedge\left(\mathrm{m}^{2}\right)$ & 1.68 & 1.7 & NS \\
\hline anti-TPO (TU/ml) & $650 \pm 250$ & $55 \pm 15$ & $* p<0.025$ \\
\hline anti-IG (IU/ml) & $360 \pm 40$ & $20 \pm 5$ & ${ }^{*} \mathrm{p}<0.006$ \\
\hline $\operatorname{TRAb}(\mathrm{U} / \mathrm{l})$ & $(+)$ & $(-)$ & \\
\hline $\mathrm{fT} 4(\mathrm{ng} / \mathrm{dl})$ & $2.04 \pm 0.3$ & $1.29 \pm 0.2$ & NS \\
\hline กl3 (ng/d1) & $3.8 \pm 0.5$ & $2,94 \pm 0,21$ & NS \\
\hline ISII ( $\mu \mathrm{IU} / \mathrm{ml})$ & $0.3 \pm 0.1$ & $1.1 \pm 0.5$ & ${ }^{*} \mathrm{p}<0.001$ \\
\hline
\end{tabular}

Table 2. Correlation between proapoptotic molecules and thyroid autoantigens (NIS and TPO) in thyroid tissues from patients with Graves'disease.

\begin{tabular}{|c|c|c|}
\hline & TIAR & TIA- 1 \\
\hline \multirow{2}{*}{ NIS } & $\mathrm{r}=0.821$ & $\mathrm{r}=0.539$ \\
& $\mathrm{p}=0.001$ & $\mathrm{p}=0.025$ \\
\hline \multirow{2}{*}{ TPO } & $\mathrm{r}=0.785$ & $\mathrm{r}=0.245$ \\
& $\mathrm{p}=0.012$ & $\mathrm{p}=0.43$ \\
\hline
\end{tabular}

(Fig. 6 and7). In addition, the degree of thyroid antigen expression was positive, and correlated with the amount of proapoptotic markers in thyroid tissues. (TIAR, $\mathrm{p}<0.001$; TIA- $1, \mathrm{p}<0.025$ for NIS; TIAR, $\mathrm{p}<0.012$ for TPO). (Table 2). However, such a correlation was not observed in patients with NTNG.

\section{Discussion}

TIA-1 and TIAR are RNA binding proteins of the RNA recognition motif (RRM)/ribonucleoprotein (RNP) family that have been implicated as effectors of apoptotic cell death. The molecular mechanism by which the PID (protein-interaction domains) of an RNAbinding protein might trigger apoptotic cell death is not fully known. Taupin et al proposed that p15TIA-1(15-kDa cytotoxic granule-associated protein) might affect the function of TIAR, a TIA-1-related RNA-binding protein what was identified by lowstringency hybridization. Like p40-TIA-1, TIAR possesses three $\mathrm{N}$-terminal RRMs and a C-terminal PID. The RRMs of TIA-1 and TIAR are in $90 \%$ identical at 


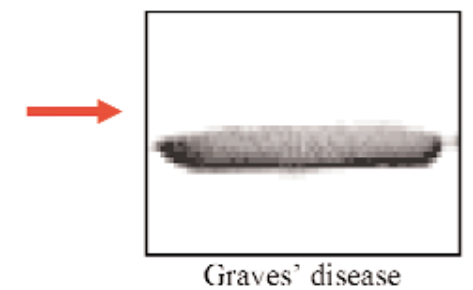

b

$42 \mathrm{kDa}$

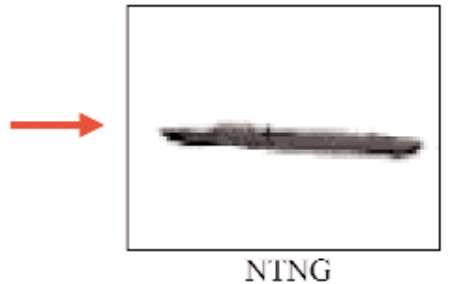

Fig. 5. Detection of $\beta$-actin obtained by Western Blot method in thyroid tissue from representative patients with Graves' disease and non-toxic multinodular goiter (NTNG); (a) expression of $\beta$-actin in patient with Graves' disease; (b) expression of $\beta$-actin in patients with non-toxic multinodular goiter.
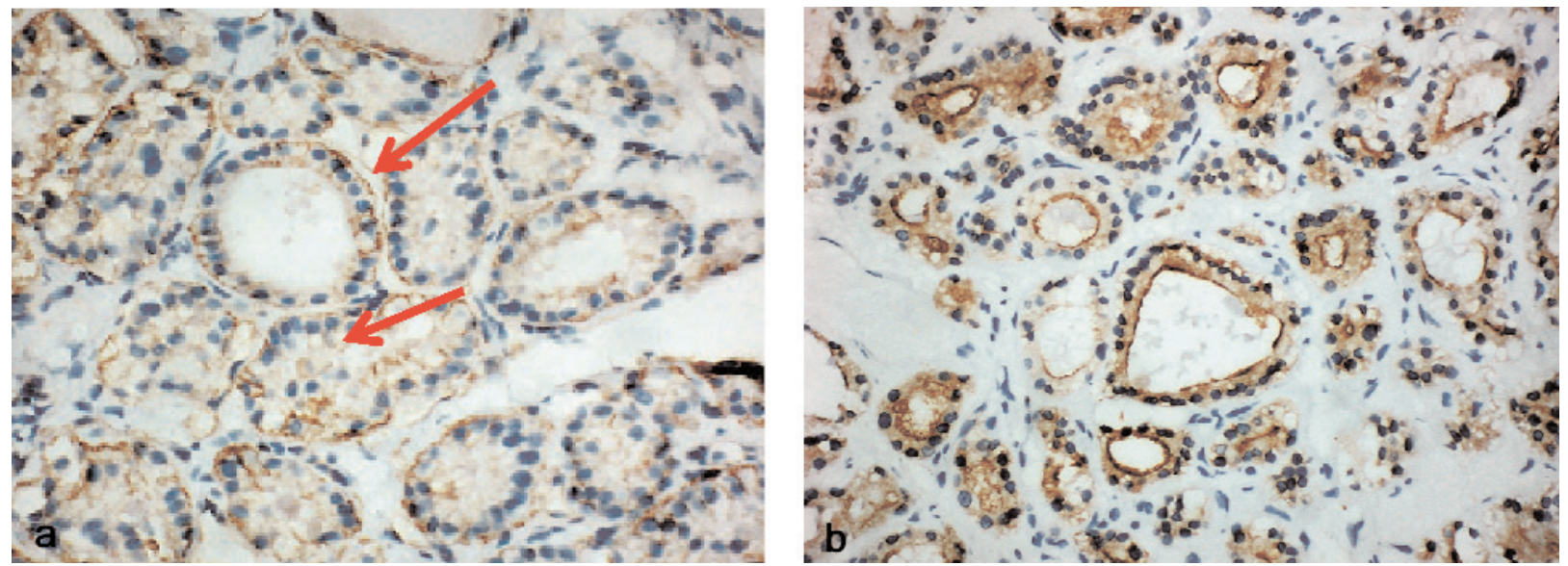

Fig. 6. Immunohistochemical identification of sodium/iodide symporter (NIS) and thyroid peroxidase (TPO) in thyrocytes from a representative patient with GD; (a) expression of NIS protein $(+++)$; (b) expression of TPO\#47 protein $(+++)$.
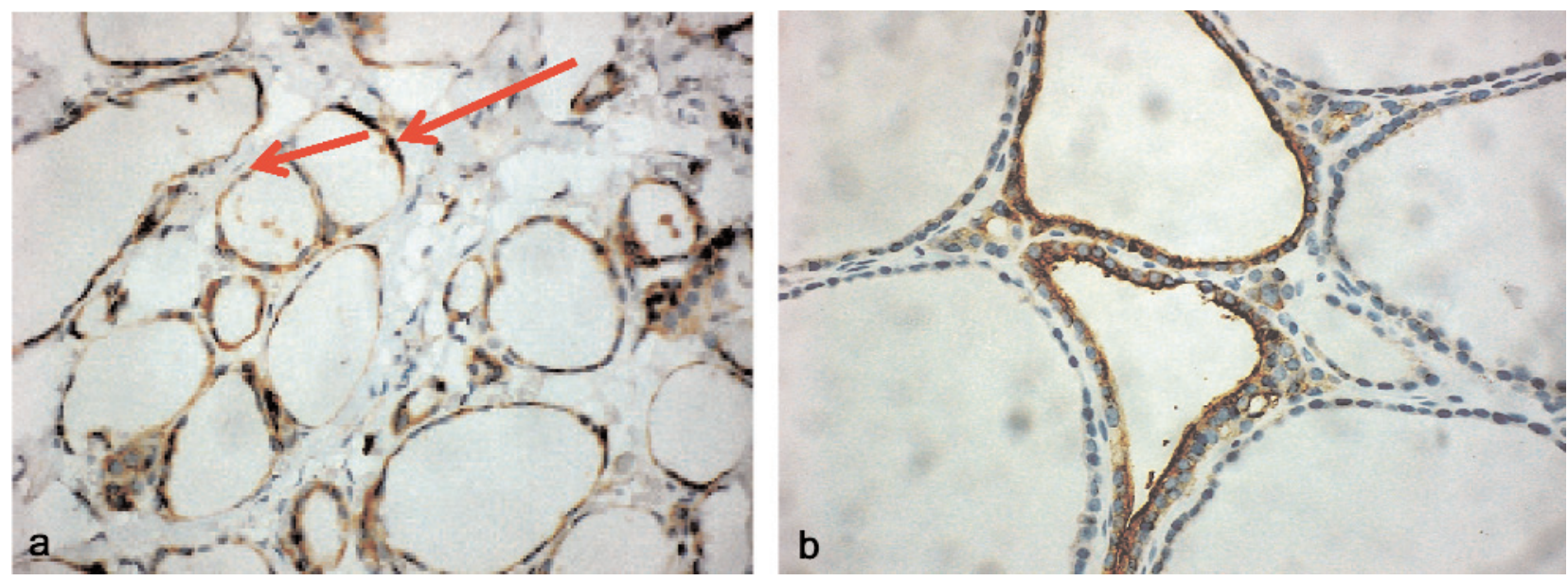

Fig. 7. Immunohistochemical identification of sodium/iodide symporter (NIS) and thyroid peroxidase (TPO) in thyrocytes from a representative patient with NTMG. (a) expression of NIS protein $(+)$. (b) expression of TPO\#47 protein $(+)$.

the amino acid level, and the PIDs are 50\% identical. Like TIA-1, TIAR triggers DNA fragmentation in permeabilized thymocytes, suggesting its possible involvement in apoptosis. Results of their study show that TIAR is a ubiquitously expressed nuclear protein that rapidly moves to the cytoplasm in response to exogenous triggers of apoptosis. TIAR is normally confined to the nucleus of cells, but during Fas-mediated apoptosis, it is rapidly translocated to the cytoplasm. Cytoplasmic redistribution precedes the onset of DNA fragmentation and the nuclear architectural changes that facilitate histone extraction [12].

Similar studies were conducted by Tain et al, who proved that TIA-1 itself has been linked to apoptosis. 
The serine-threonine kinase FAST is activated during Fas-mediated apoptosis in Jurkat cells and phosphorylates TIA-1 prior to the onset of DNA fragmentation [13].

In the mouse model TIAR were essential for primordial germ cell development, as it appears to be necessary for cell survival [14]. It may be suggest that proapoptotic stimuli modify the activities of TIA-1 and TIAR, leading to changes in the splicing patterns of key pre-mRNAs.

Tsuzuki et al showed that apoptosis triggered by 20-hydroxyecdysone during pupal metamorphosis of the silkworm Bombyx mori is accompanied by an increase in TIAR mRNA levels [15]. Jin K. et al indicated that ischemia-induced apoptosis also leads to an increase in TIAR mRNA levels [16]. These observations also suggest that TIAR could be required for apoptosis. TIA-1 and TIAR may normally work for cell survival, but during apoptosis they are modified, so as to be rendered inactive for cell survival tasks, yet active to participate in new tasks in apoptosis progression [17].

The role of TIA and TIA-1 hasn't been explained in thyroid autoimmunological diseases. Immunohistochemistry revealed that lymphoid cells may be positive for T-cell-restricted intracellular antigen 1 (TIA1). Okamoto et al. described a case of patient with Tcell lymphoma without clinical or laboratory symptoms of autoimmune thyroiditis. They suspected that TIA-1 expression together with TCRb gene rearrangement seemed categorized into TCRa/b+ cytotoxic T-cell lymphoma. Although Yamaguchi et al. reported a case of TCRg/d+ thyroid T-cell lymphoma, no case of thyroid T-cell lymphoma expressing cytotoxic molecules such as TIA-1 has been reported $[18,19]$.

In our studies elevated expression of TIAR/TIA-1 in GD in comparison with its expression in nonimmune diseases indicated to enhanced apoptosis activity in immune process. Our findings suggest that significant expression of TIAR may indicate on enhanced activity of egzogenous way of apoptosis in autoimmune diseases, for example in GD. Kawakami et al observed the association between the apoptosis of thyrocytes and the process of autoimmune thyroid diseases and suggested that Fas-mediated apoptosis of human thyrocytes is modulated by thyroid-stimulating antibodies, thyroid stimulation blocking antibodies and cytokines [20]. Similarly, we conclude that elevated expression of NIS and TPO in Graves' disease is associated with higher stimulation and activation of apoptosis in thyroid follicular cells during autoimmune process. According to our knowledge the correlation between NIS and TPO and apoptosis regulatory molecules of the TIA-1 family in thyroid diseases was not considered in any publication. Therefore more and more observations are needed. The understanding of the apoptotic process at the molecular level may broaden the knowledge of the pathogenesis of autoimmune thyroid disorders and provide new diagnostic, prognostic and therapeutic potentials.

We conclude that elevated expression of NIS and TPO in Graves' disease is associated with higher stimulation and activation of apoptosis in thyroid follicular cells during autoimmune process.

\section{References}

[1] Beck AR, Medley QG, O'Brien S, Anderson P, Streuli M. Post-transcriptional regulation of tumour necrosis factor $\alpha$ production. Nucleic Acids Res. 1996;24:3829-3835.

[2] Förch P, Puig O, Kedersha N. et al. Modulation of msl-2 5' splice site recognition by Sex-lethal. Mol Cell. 2000;6:10891098.

[3] Förch P, Puig O, Martnez C, Seraphin B, Valcarcel J. U2 small nuclear ribonucleoprotein particle (snRNP) auxiliary factor of $65 \mathrm{kDa}, \mathrm{U} 2 \mathrm{AF} 65$, can promote $\mathrm{U} 1 \mathrm{snRNP}$ recruitment to 5' splice sites. EMBO J. 2002;21:6882-6892.

[4] Piecyk M, Wax S, Beck AR. et al. Post-transcriptional regulation of tumour necrosis factor $\alpha$ production. EMBO J. 2000; 19: 4154-4163.

[ 5] Yu Q, Cok SJ, Zeng C, Morrison AR. Translational Repression of Human Matrix Metalloproteinases-13 by an Alternatively Spliced Form of T-cell-restricted Intracellular Antigenrelated Protein (TIAR). J Biol Chem. 2003;278:1579-1584.

[6] Dixon DA, Balch GC, Kedersha N. et al. Regulation of Cyclooxygenase-2 Expression by the Translational Silencer TIA-1. J Exp Med. 2003;198:475-481.

[7] Kandasamy K, Joseph K, Subramaniam K, Raymond JR, Tholanikunnel BG. Translational Control of \{beta\}2-Adrenergic Receptor mRNA by T-cell-restricted Intracellular Antigen-related Protein. J Biol Chem. 2005;280:1931-1943.

[ 8] Kawai T, Lal A, Yang X, Galba'n S, Mazan-Mamczarz K, Gorospe M. T-cell Intracellular Antigen-1 (TIA-1)-induced Translational Silencing Promotes the Decay of Selected mRNAs. Mol Cell Biol. 2006;26:3295-3307.

[ 9] Lal A, Abdelmohsen K, Pullmann R et al. Post-transcriptional derepression of GADD $45 \alpha$ by genotoxic stress. Mol Cell. 2006;22:117-128.

[10] Izquierdo JM, Valcarcel J. Two Isoforms of the T-cell Intracellular Antigen 1 (TIA-1) Splicing Factor Display Distinct Splicing Regulation Activities. Biochem Biophys Res Commun. 2006;348:703-711.

[11] Beck AR, Medley QG, O'Brien S, Anderson P, Streuli M. Structure, tissue distribution and genomie organization of the murine RRM-type RNA binding proteins TIA-1 and TIAR. Nucleic Acids Research. 1996;19:3829-3835

[12] Taupin J, Tian Q, Kedershat N, Robertson M, Anderson P. The RNA-binding protein TIAR is translocated from the nucleus to the cytoplasm during Fas-mediated apoptotic cell Heath. Proc Natl Acad Sci USA. 1995; 92:1629-1633.

[13] Tian Q, Taupin J, Elledge S, Robertson M, Anderson P. Fasactivated serine/threonine kinase (FAST) phosphorylates TIA-1 during Fas-mediated apoptosis. $J$ Exp Med. 1995;182: 865-874.

[14] Beck A, Miller I J, Anderson P, Streuli M. RNA-binding protein TIAR is essential for primordial germ cell development. Proc Natl Acad Sci USA. 1998; 95:2331-2336.

[15] Tsuzuki S, Iwami, M, Sakurai S. Ecdysteroid-inducible genes in the programmed cell death during insect metamorphosis. Insect Biochem Mol Biol. 2001;31:321-331. 
[16] Jin K, Mao XO, Eshoo MW. cDNA Microarray Analysis of Changes in Gene Expression Induced by Neuronal Hypoxia in Vitro. Ann Neurol. 2001;50:93-103.

[17] Le Guiner C, Gesnel MC, Breathnach R. TIA-1 or TIAR Is Required for DT40 Cell Viability. $J$ Biol Chem. 2003;12:10465-10476.

[18] Yamaguchi M, Ohno T, Kita K. g/d T-cell lymphoma of the thyroid gland. NEJM. 1997;336:1391-1392.
[19] Namura K, Uchiyama H, Kajita Y, Inaba T, Nakamura S, Shimazaki C. Cytotoxic T-Cell Non-Hodgkin's Lymphoma of the Thyroid Gland Akio Okamoto. Am J Hematol. 2005;8:77-78.

[20] Kawakami A, Eguchi K. Involvement of apoptotic cell death in autoimmune diseases. Med Electron Microsc. 2002;35:1-8.

Submitted: 3 January, 2010 Accepted after reviews: 29 March, 2010 